\title{
Smart Tracking System to Locate Student and Vehicle in Schools
}

\author{
Dr.R.Athilingam ${ }^{1}$, R.Kowshick ${ }^{2}$, M.Jeeva ${ }^{3}$ \\ Associate Professor, Department of Electronics and Communication Engineering, \\ Nadar Saraswathi College of Engineering and technology, Theni, India ${ }^{1}$ \\ BE Students, Department of Electronics and Communication Engineering, \\ Nadar Saraswathi College of Engineering and Technology, Theni, India ${ }^{2,3}$
}

\begin{abstract}
In current scenario due to increase in kidnapping of kids and road accidents, Parents feel much worried about the safety of their children. They always seek a solution to track the presence of their kid once they depart from home to school. Thus, we propose a SMS based solution to help parents to know their children arrival and time of departure during their school days. Accident detection sensors are implanted on the front surface of the school bus to detect collision with another vehicle on the road. Each student is tagged with a unique code. The code will be recognized by the RFID system. If the bus journey is not harmful from the source to destination, the GSM will send an SMS to the management and parents to inform its departure and arrival status of the
\end{abstract}

Keywords: Bus Safety System, RFID (Radio Frequency Identification), GSM modem, GPS

\section{INTRODUCTION}

School children safety is the most awaited research needed for present age with the support of advanced technology. We have developed working model with RFID Technology and a PIC 16F877A microcontroller and GSM technology. The Entry and Exit status of the children is primarily fed and made available with school principal and with the parents. The proposed article describes a bus safety system to control the entry and exit of students from the bus. These systems identify personal information of each student using RFID tag, via radio waves and display each student name into LCD display. The IR sensor is used to monitor the total count of the students. This will help the driver to know count of students inside the bus and the students who departed from the bus. If the bus depart and arrive successful from the source to destination, it will communicate the management through an SMS about successful departure and arrival via GSM Modem. Moreover, the system has an emergency setup to alert in case if there is any accident by sending an SMS to the school management via GPS System.

\section{LITERATURE REVIEW}

Maryam Said Al-Ismaili [2] proposed a system capable to control the entry and exit of students in bus using RFID tag and GSM technologies to ensure the entry and exit in based on attendance in safer manner. K. Vidyasagar [5] et al have designed the working model with RFID Technology and an advanced ARM 7 processor and GSM technology. The status of the children is pre-written and readily available with the school principal and with the parents. Wireless technology (IEEE 802.4.15) is used to inform the status of the bus to the school.

A. Abdullah [1] et al, implemented an Android based solution to support and help parents to track their children in real time environment. The system is equipped with location sharing capabilities helping to get the device's geographic position in real time. Mahesh Kadibagil[3] developed an Autonomous target detection and tracking system that enhances the accuracy of locating a particular person position by using GPS information and standard web technology. This system includes a mobile client, a database repository, a web client and a map service. In the tracking system designed by Khaled[4], he utilized the passive RFID tracking technology since it has efficient tracking capabilities, low cost, and easy maintenance. It works to provide secure transportation in school bus equipped with RFID technology.

\section{HARDWARE COMPONENT DESCRIPTION}

The following are the major components which are used in the GSM based school bus transportation system using RFID 
[1]. IR sensor

[2]. Piezoelectric vibration sensor

[3]. RFID Tag

[4]. RFID Reader.

[5]. PIC 16F877A Microcontroller

[6]. GSM modem

[7]. GPS module

[8]. LCD display

[9]. keypad

IR SENSOR: It has of an emitter, detector and associated circuitry. The circuit has two parts; the emitter and receiver circuit. The basic concept behind IR(infrared) is to transmit IR signal in a direction and received at IR receiver when the IR radiation reflects back from a surface of the object. An IR sensor is placed in the bus to detect presence of students inside the school bus. In our proposed system IR sensor is used to increase the count according to presence of the students.

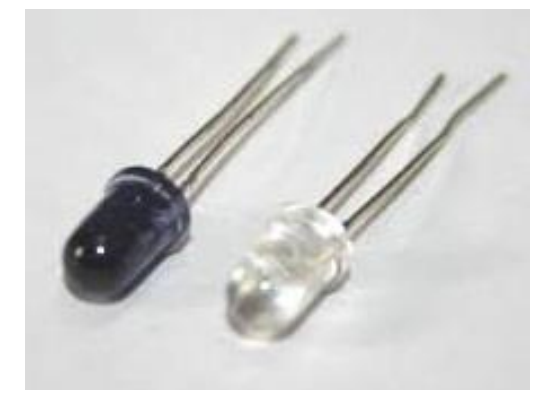

Figure 1.IR Sensor

PIEZO ELECTRIC VIBRATION SENSOR: A Piezoelectric Vibration Sensor is placed in bus to detect collision with another vehicle on the bus. The proposed system uses a piezo -electric sensor which can detect random and abrupt vibration when accident occurrs. This sends a signal to microcontroller and the Emergency message is sent to the school management. It works on piezoelectric effect which measures the changes in pressure, acceleration and force by converting them into electrical charge. When Accident occurs, piezo electric detects the vibrations based GSM module sends messages to authorized users.

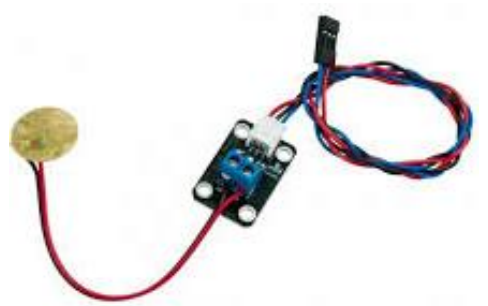

Figure 2. Piezo Electric Vibration Sensor

RFID TAG: Each student is given with an RF identity card. The Tag contains all the information about student such as Name, Address, Phone number. The indentifying information stored in the microchip is transmitted to the RFID reader using an antenna. RFID reader is equipped at the entrance and exit of the bus. The reader will communicate to PIC16F877A microcontroller serially using the line driver EM4001 to verify the threshold value.

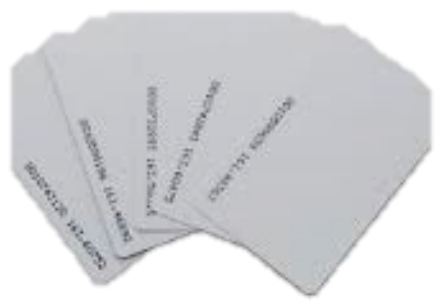

Figure 3 RFID Tag 
RFID READER: RFID Tag reader is operated at $125 \mathrm{KHz}$ with serial format. A switch is available to select output format. Easy interface to computer serial terminal through DB9 connector or direct interface to microcontroller via onboard connectors is done. Then operating voltage is $5 \mathrm{v} \mathrm{dc}$ and operating frequency is $125 \mathrm{kHz}$.

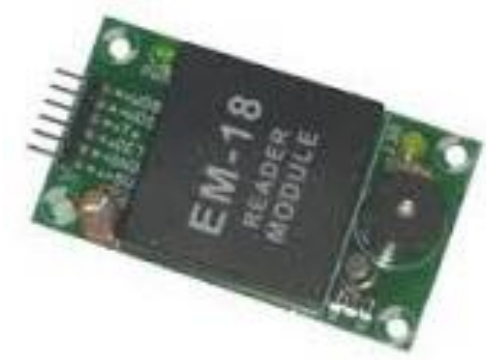

Figure 4 RFID Reader

PIC 16F877A MICROCONTROLLER: The controller IC has two 8 bit registers, an instruction register (IR) and a data register (DR). The IR stores the instruction codes and address information for display data RAM (DD RAM) and character generator RAM (CG RAM). The IR can be written, but not read by the MPU. The DR temporally stores data to be written to read from the DD RAM or CG RAM. The data written to DR by the MPU, is automatically written to the DD RAM or CG RAM as an internal operation. When an address code is written to IR, the data is automatically transferred from the DD RAM or CG RAM to the DR..

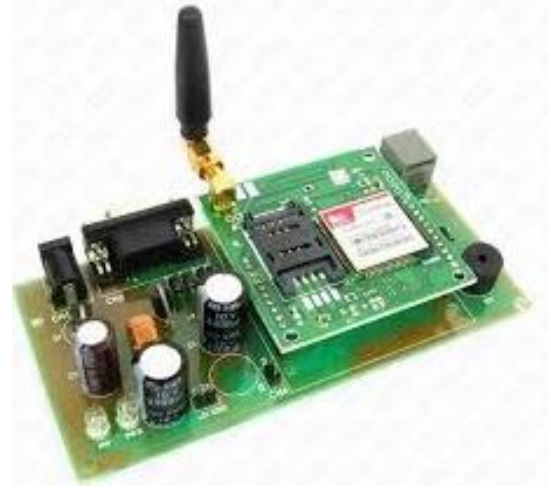

Figure 5 GSM Modem

GPS MODULE: GPS Module deals with position based services by determine the longitude, altitude and latitude. Using this module, school management can find the location of the bus. Incase any accident occurs, it will helps to find the location of the school bus. The location found by the GPS module sends the message through GSM to the appropriate phone number.

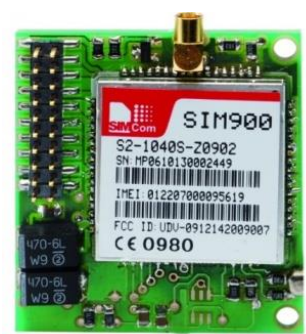

Figure 6 GPS Module

LCD DISPLAY: An LCD consists of two glass panels, with the liquid crystal material sand witched in between them. When the LCD is in the off state, light rays are rotated by the two polarisers, such that the light come out of LCD without any orientation, becoming transparent. The light rays passing through the LCD would be rotated by the polarisers, which would result in activating highlighting the desired characters .In this proposed system, $16 * 2 \mathrm{LCD}$ panel would be used to display the values 
Vol. 8, Issue 1, January 2019

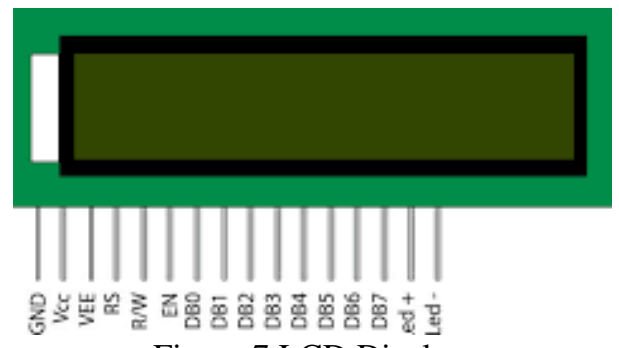

Figure 7 LCD Display

KEYPAD:In this proposed system we used $3 * 3$ keypad is used to edit the phone number of the students. Else any other modification is required we can use this keypad.

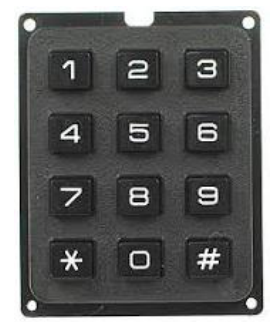

Figure 8 Keypad

\section{IMPLEMENTATION AND RESULTS}

In our proposed system we have implemented based on the block diagram described in figure 9 . The results are shown in figure 10 .

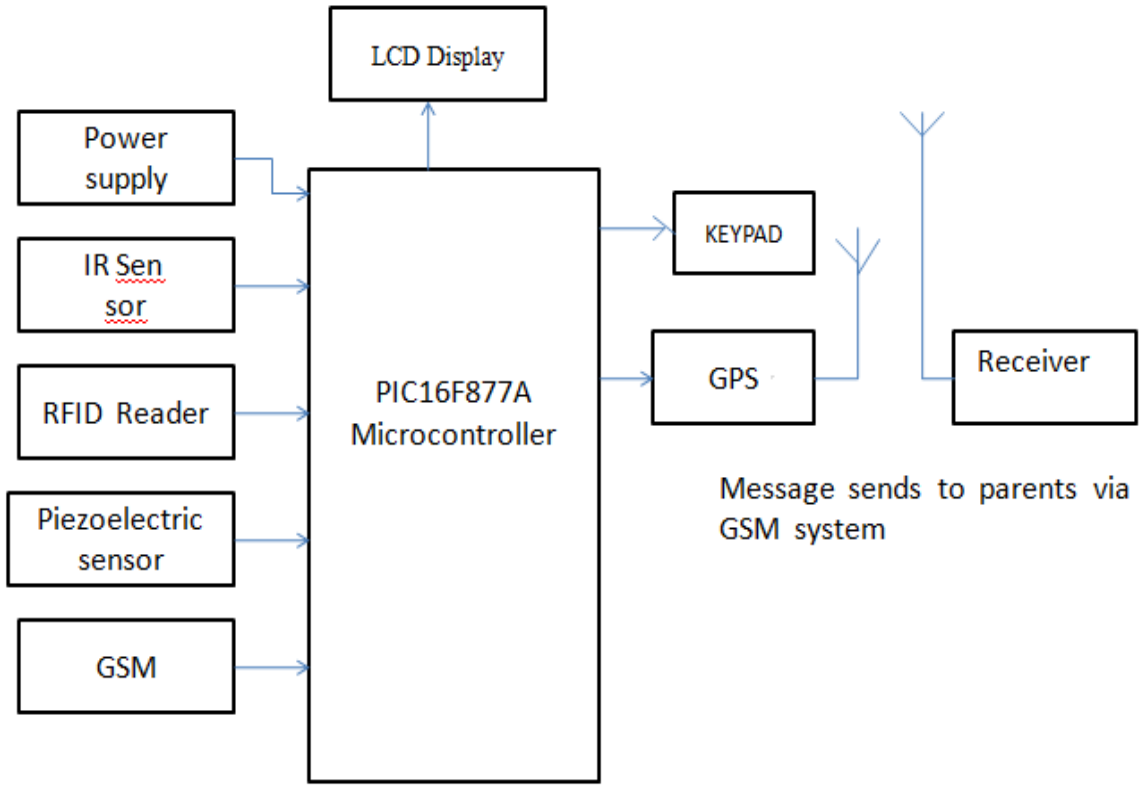

Figure 9 - Block Diagram

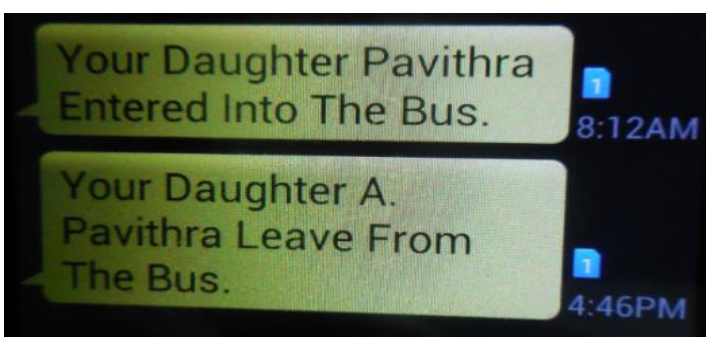

Figure 10 Notification to Parents 
Vol. 8, Issue 1, January 2019

\section{CONCLUSION}

Thus, In this project, bus safety system for school children has been developed. Using this system, the school authorities, bus driver can be given alert from the RFID card. At the same time, in case if there is a student did not enter into the bus, the system will send an SMS to the management of the school to take the right decision. The paper shows that that RFID technology based tracking system is the best solution to enhance the safety in the school buses, which will reduce the incidents of forgetting the students inside the bus.

\section{REFERENCES}

[1]. M.F.A bdullah, "Child Tracking System Using Smart phone" International Journal of Electrical, Computer, Energetic, Electronic and Communication Engineering Vol:7, No:2, 2013.

[2]. Maryam Said Al-Ismaili , "Bus Safety System for School Children Using RFID and SIM900 GSM MODEM" International Journal of Latest Trends in Engineering and Technology Vol. 5 Issue 1 January 2015

[3]. Mahesh Kadibagil,"Position Detection and Tracking System", published in IRACST - International Journal of Computer Science and Information Technology \& Security (IJCSITS),Vol. 4, No. 3,June 2014.

[4]. Khaled Shaaban et.al, "Smart Tracking System for School Buses Using Passive RFID Technology to Enhance Child Safety “ , Journal of Traffic and Logistics Engineering, Vol 1( 2): pages 191-196, Dec 2013.

[5]. K. Vidyasagar "RFID-GSM imparted School children Security System" Communications on Applied Electronics (CAE) - ISSN : 2394-4714 Foundation of Computer Science FCS, New York, USA Volume 2 - No.2, June 2015

[6]. V.Sivasankaran et.al , "Advanced embedded system assisted GSM and RFID based smart school management system", International journal of advanced research in electrical, Electronics and Instrumentation Engineering, Vol 2(7): pages 3124-3128, July 2013

[7]. Nitin Shyam, "SMS Based Kids Tracking and Safety System by Using RFID and GSM"IJISET - International Journal of Innovative Science, Engineering \& Technology, Vol. 2 Issue 5, May 2015.

[8]. Mohammed Abdul Qadeer,"Design and Implementation of Location Awareness and Sharing System using GPS and 3G/GPRS" published in International Journal of Multimedia and Ubiquitous Engineering Vol. 7, No. 4, October, 2012 .

[9]. Stephen S. Intille, "Design And Development Of A PIC 16F877A Based Patient Monitoring System"

[10]. Athilingam R, Mohamed Rasheed A, Senthil Kumar K, "Design and Implementation of a Multirotor Unmanned Aircraft System for Target Tracking", Arab J Sci Eng (2017) 42:1737-1749 